\section{A model of how children construct knowledge and understanding of engineering design within robotics focused contexts}

\section{Yuen, Timothy T.}

Department of Interdisciplinary Learning and Teaching, University of Texas San Antonio, USA (Timothy.yuen@utsa.edu)

Stone, Jennifer

Department of Curriculum and Instruction, Wichita State University, USA (Jennifer.stone@wichita.edu)

Davis, Don G.

Department of Interdisciplinary Learning and Teaching, University of Texas San Antonio, USA (Dondavis@reglue.org)

Gomez, Alvaro

Department of Interdisciplinary Learning and Teaching, University of Texas San Antonio, USA (Alvaro_gomez2002@hotmail.com)

\section{Guillen, Adrienne}

Department of Interdisciplinary Learning and Teaching, University of Texas San Antonio, USA (adrienneguillen@gmail.com)

Price Tiger, Erin

Department of Interdisciplinary Learning and Teaching, University of Texas San Antonio, USA (ceres18@yahoo.com)

Boecking, Melanie

Department of Interdisciplinary Learning and Teaching, University of Texas San Antonio, USA (melanieboecking@gmail.com)

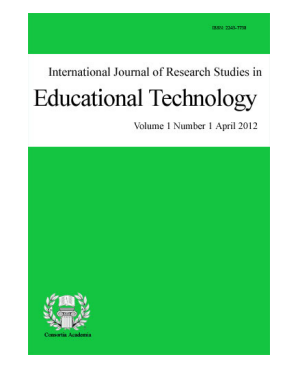

ISSN: $2243-7738$ Online ISSN: 2243-7746

OPEN ACCESS

Received: 10 June 2015

Revised: 9 July 2015 DOI: $10.5861 /$ ijrset.2015.1266

\title{
Abstract
}

The use of robotics to support instruction and learning has gained increasing attention from many areas of educational research. Researchers conducted a qualitative examination of elementary and middle school students' approaches to engineering design in the context of a summer robotics camp. Analyses of the findings were used to generate a grounded theory indicating that two complementary conceptual frameworks in engineering design with respect to robotics activities guide students. Namely, students' understanding of robots is facilitated by embodied cognition and systems thinking approaches. This study presents a potentially significant finding as both embodied cognition and systems thinking have been identified as significantly beneficial in supporting students' science, technology, engineering, and math (STEM) learning.

Keywords: engineering design; educational robotics; design process; decision making 


\section{A model of how children construct knowledge and understanding of engineering design within robotics focused contexts}

\section{Introduction}

There has been an ongoing push to increase the number of students pursuing careers in science, technology, engineering, and math (STEM) in the US due to a shortage of engineers compounded by a lack of diversity among engineering students (Lord et al., 2009; National Science Foundation, 2015; Ohland, Sheppard, Lichtenstein, Chachra, \& Layton, 2008). STEM education efforts are important to fulfilling domestic labor demands as well as addressing the substantive underrepresentation of various demographic groups in STEM fields (Lord et al., 2009; Tornatzky, Macias, \& Jones, 2002). Many approaches have focused on creating awareness of and generating interest in STEM among younger students to address participation issues early on in the engineering education pipeline (Moffett, Weis, \& Banilower, 2011). Such efforts prepare students for life-long learning trajectories that are significantly influenced at early ages (Tai, Liu, Maltese, \& Fan, 2006). Accordingly, some programs sought to engage youth with engineering and other STEM fields by providing hands-on learning activities and opportunities (Goldman, Eguchi, \& Sklar, 2004; Moffett, Weis, \& Banilower, 2014).

Engineering and other design activities exemplify such hands-on approaches. Consequently, educators have sought to improve students' understanding by engaging them in activities grounded in design (e.g. Kolodner, Camp, Crismond, Fasse, Gray, \& Holbrook, 2003) and systems thinking approaches (e.g. Goldstone \& Wilensky, 2008) as well as the two approaches in conjunction with one another (e.g. Hmelo, Holton, \& Kolodner, 2000). These approaches motivate students by engaging them in authentic learning experiences within engineering contexts that are similar to those found in the real world. Such active learning and exploration have shown positive results in student motivation and problem solving ability with undergraduate computer students (Reza \& Ijaz Baig, 2015).

Engineering design goes beyond problem solving by considering the dynamics and complexities of real world problem spaces (Committee on K-12 Engineering Education, 2009). Moreover, the complexity of such problem spaces necessitates that engineers engage in "decision making with incomplete knowledge" (Yao \& Roesset, 2001, p. 313). As such, engineering design activities are pedagogically advantageous for many reasons, especially in that they require students to think beyond prescribed problem solving activities and engage with the complexities of the real world (Katehi, Pearson, \& Feder, 2009). Rather than work through sets of highly structured problems, students must utilize and develop strategies to solve unstructured problems within a dynamic environment, which is much more reflective of real world problems (Mehalik, Doppelt, \& Schuun, 2008). The process is highly beneficial to students as it provides a more natural context to develop several key cognitive skills and a knowledge base crucial for success in STEM and STEM related fields (Slangen, Keulen, \& Gravemeijer, 2011; Williams, Ma, Prejean, Ford, \& Lai, 2008).

Consequently, the goal of this research was to discover how students construct knowledge and understanding while engaged in hands-on motivating engineering design activities within a robotics-focused context. Specifically, students' behaviors while engaged in robotics-focused engineering design are analyzed and synthesized to develop a grounded theory of how novices approach such tasks.

\section{Engineering Design}

Robotics promotes authentic, concrete, and hands-on approaches to solving real world engineering problems. Frequently, students are required to go through an iterative design process whereby they modify robots in attempts to better complete certain tasks and surmount certain obstacles, often in competition against others 
A model of how children construct knowledge and understanding of engineering design

(Verner \& Ahlgren, 2004). Such design oriented activities align strongly with related research that highlights the efficacy of utilizing design based approaches to supporting students' understanding of engineering concepts and processes (Hmelo et al., 2000). During engineering design projects, students are asked to develop solutions and improve understandings while working through an iterative process of identifying and remedying potential shortcomings. These findings highlight the potential efficacy of robotics and other non-traditional engineering design activities as ways to improve STEM instruction for young learners (Bers, 2010; Goldman et al., 2004).

\subsection{Complementary Theoretical Frameworks}

Researchers have indicated that cognitive processes, such as systems thinking (Goldstone \& Wilensky, 2008; Wilensky \& Resnick, 1999) and embodied cognition (Núñez, Edwards, \& Matos, 1999; Wilson, 2002), allow students to construct more complex systems and complete more elaborate tasks (Hmelo et al., 2000). Identifying how these processes work together in engineering design tasks may ultimately result in improved instruction and pedagogy in STEM fields.

Among the cognitive affordances of engaging students in engineering projects, students must develop solutions and improve understandings while working through an iterative process, whereby they are forced to reassess and revise their thinking (Hmelo et al., 2000). Such understanding of how individual components work together to form emergent complexity is the essence of systems thinking (Anderson \& Johnson, 1997; Blikstein, Rand, \& Wilensky, 2007). Systems thinking approaches have been utilized in conjunction with design tasks as they provide learners with a more holistic view of the tasks and problem space (cf. Assaraf \& Orion, 2010; Frank, 2002; Yurtseven \& Buchanan, 2012).

Complementing systems thinking, engineering design can be supported by familiarity through discussions of embodied cognition in which problem solving processes "are themselves further situated and made comprehensible by the shared biology and fundamental bodily experiences of human beings" (Núñez et al., 1999, p. 65). Essentially, embodied cognition reflects the realization that cognition is "deeply rooted in the body's interaction with the world," which can lead to varying conclusions, interpretations, and assumptions (Wilson, 2002, p. 625). Moreover, the assertion that cognition is informed by corporality has significant importance for the learning sciences and the development of pedagogy (Núñez et al., 1999; Wilson, 2002). Research has shown that embodied cognition undergirds even the most complex of mathematical understandings (Núñez et al., 1999), and also forms the conceptual basis for all other understandings (Lakoff \& Johnson, 1999; Lakoff \& Núñez, 2000). It is expected that by unearthing connections between embodied cognition and the comprehension and articulation of complex content area concepts, engineering education researchers will be able to broaden understanding of the learning process and strengthen pedagogical practices (cf. Howison, Trninic, Reinholz, \& Abrahamson, 2011).

The connections among embodied cognition, systems thinking, and learning in engineering are undeveloped and would benefit from further clarification. It is unclear to what extent younger students might connect such cognitively significant elements in varying contexts such as engineering design activities. Thus, the discovery of such connections during an exploratory study examining students while engaged in a robotics-focused engineering design activity could prove beneficial to the development of more effective instruction in STEM education and the broader learning sciences.

\subsection{Research Question}

The findings presented here are intended to address the question of: How do children construct knowledge and understanding of engineering design as facilitated by robotics projects and activities?

\section{Methods}

This study adopted a grounded theory methodology to investigate what facilitates and informs children's 
engineering design through robotics. Grounded theory provides a set of systematic guidelines that focus on the creation of emerging theory to describe a phenomenon while collecting and analyzing data (Glaser \& Strauss, 1967; Strauss \& Corbin, 1998). This study's grounded theory design was built upon the variation of Strauss and Corbin (1998), who emphasized verification and creating connections between categories while adding axial coding, and suggested proposing connections between conditions.

\subsection{Setting}

The study took place at a summer robotics day camp held at a large university in south Texas in the summer of 2011. There were nine robotics sessions: four sessions for elementary school students (3rd-5th grade) and five sessions for middle school students (6th-8th grades) were offered throughout the summer. Each camp session lasted 5 days, Monday through Friday from $8 \mathrm{am}$ to $4 \mathrm{pm}$. One robotics session for each grade level was offered each week. The robotics camps blended formal and informal instruction. There were two or three instructors per camp session. Instructors were assigned to a camp at either grade level each week. Instructors were either undergraduate students in a STEM major or instructors specifically employed by the university for this camp.

Throughout each week, students learned how to build and program robots using the LEGO Mindstorms NXT kit. Children worked in groups of 3 to 5, with each group sharing one robotics kit and a desktop computer. Instructors started each day with direct teaching of the concepts needed for the day. After the initial formal instruction, the students were engaged in a self-directed, hands-on group activity and the instructors became facilitators of the activity. Instructors designed challenges that required the robots to complete several tasks. Students worked in small groups to design, build, and program robots that accomplished the tasks designed by the instructors. Finally, mini-competitions were held at the end of each day to see which groups' designs were implemented best. Such competitions included navigating through courses with or without obstacles, going through courses and moving items from one place to another, and sumo-robot competitions whereby robots had been constructed to push an opposing robot out of the ring.

This study was approved by the researchers' university Institutional Review Board (IRB). The researchers were granted permission to recruit students by the STEM education center that operates these summer camps at the university. Additionally, researchers were granted permission to observe classrooms that included participants.

\subsection{Participants}

Forty-three children participated in this study $(n=43)$. Researchers recruited children and obtained parental consent and minor consent/assent as students checked in for the robotics camps on the first day (Monday) of each camp. Twenty-five children in the elementary camps (3rd to 5th grade) and 18 children in the middle school camps (6th to 8th grade) agreed to participate in the study. Each participant was given a number (\#) and referred to as $\mathrm{P \#}$ in analyses and in this paper.

\subsection{Data Collection}

Observations and semi-structured interviews were collected for analysis. Seven researchers worked to conduct individual observations of participants engaged in robotics tasks. Field notes were made of participants' actions and discourse occurring during robotics activities. Three 30-minute observations were conducted for each participant, which resulted in about 3870 minutes of observation time. The researchers did not interfere with the participants' work during these observations. Researchers conducted three individual semi-structured interviews with each participant during the week. Interviews were conducted while participants were working on robotics tasks and occurred after participants had had at least one full day of designing, building, programming, and testing robots. Interviews began with general questions, such as: What are you doing? What is this part [of the robot] and what does it do? and Why is that part needed? Probing questions were asked to delve into more detail about participants' understanding of the task requirements and robotics concepts. Interviews varied in 
A model of how children construct knowledge and understanding of engineering design

length from 3 to 15 minutes depending on participant's availability and willingness to talk. All interviews were recorded digitally and transcribed.

\subsection{Analysis}

Analysis began with open coding of interview transcriptions in which each phrase was coded based on description, meanings, and themes (Strauss \& Corbin, 1998). This micro-analytic approach is intended to facilitate new questions about and interpretations of the phenomena being studied as well as give a voice to the participants (Strauss \& Corbin, 1998). Here, researchers first constructed an initial set of labels to describe each data fragment that then further informed the coding process. Afterward, through constant comparison (Glaser, 1965), researchers were able to develop and refine a set of labels describing most of the data. This constant comparison included researchers meeting throughout the study to discuss the labels, their conceptual implications, and significance to the overall observations. Memos that described the major codes used were continually updated and revised throughout the entire analytic process (Strauss \& Corbin, 1998).

After many rounds of refinement, five major categories emerged that could succinctly describe how these particular children constructed knowledge and understanding of engineering design as facilitated by robotics projects and activities. Namely, the open coding process yielded the following categories: systems thinking, associations with prior knowledge, design decisions, challenges faced in robotics, and perception of control over the robots. Each of these categories is later described in further detail.

In axial coding, the researchers found that the relationships among the categories' could be traced back to children's articulation of robotics, evidencing epistemologies grounded in systems thinking and embodied cognition. In the final stage of selective coding, systems thinking and associations were identified as the most appropriate and central categories to explaining how children construct knowledge and understanding of engineering design within robotics focused contexts.

Trustworthiness - Several strategies were employed to ensure the trustworthiness of the findings including triangulation with field notes and memos, prolonged engagement, and peer debriefing (Shenton, 2004; Strauss \& Corbin, 1998). Researchers conducted field observations of the participants as they were working on their projects. Field notes included a list of participants' actions as well as descriptions of general tasks and activities. There was prolonged engagement with the robotics clubs as the research team was present and conducting research throughout the duration of the robotics camps. The research team was already familiar with the camp operations and staff by the time data collection started for this study during the pilot phase. The research team met periodically to discuss the results of these analyses throughout the data collection and analysis phases, whereby they came to consensus on the formation of categories. Building on field observations and interviews, the research team debated the existence, description, and importance of all initial categories. The memos describing the formation of the major categories (Strauss \& Corbin, 1998) were written during such meetings. The findings presented in this study are the result of research team consensus.

\section{Results}

The grounded theory analysis indicated that children's construction of knowledge and understanding of engineering design within a robotics-focused context was primarily guided by systems thinking and embodied cognition perspectives. In summary, researchers discovered that: In order to construct knowledge of and understand engineering design tasks within robotics focused contexts, children are guided by two complementary conceptual frameworks for understanding robots: 1) through thinking of the robot as a system of interrelated parts (systems thinking) and 2) through scaffolded understandings of the robot rooted in the students' own physicality (embodied cognition).

The resultant grounded theory highlights five major aspects of engineering design and robotics focused contexts: a) the approach that children cognitively use in engineering design in robotics; b) the combination of 
systems thinking and embodied cognition (associations) perspectives that children used to understand engineering design; c) the centrality of the iterative approach they take to design decisions; d) the function of challenge in relation to student learning in engineering design tasks; and e) the role of students' sense of control over the robot. To better explain the development of this theory, a discussion on the formation of each category is provided.

\subsection{Systems Thinking}

Participants adopted a systems thinking conceptual framework to understand the design of their robot. Participants recognized that a system constituted a set of components and each component were related to and interacted with each other. Participants understood that a robot was a system of its sensors, motors, brick, and other parts.

The brain is like the computer for the robot... Without the brain you can't make it do anything...There's the brain, there's the motors, there's the tires, there's the... all the things that connect it (P27).

You could put [the ultrasonic sensor] anywhere you wanted as long as it could connect to the brain (P28).

The brain has like all the memory like a real brain does and it has like, like you have to have the cables to like plug it in and like plug it into the cables so it can, so it can work (P35).

Though the identification of system elements was part of the researchers' line of questioning, participants appeared to do more than just identify and describe what each part does. As demonstrated above, they also made connections between specific parts and the rest of the robot in terms of purpose and functionality.

The analogy of robots as living beings with organs helped participants understand how different system elements worked together. This showed that participants had constructed higher-level understanding including a broader view of what the designs should accomplish with regards to the individual system components therein. Namely, participants understood the robots' design as a system of related and interconnected parts. Specifically, students' discussion of robots in the design process reflected elements of embodied cognition. Participants indicated that the brick, as the "brain," worked in conjunction with other parts of the robot, such as the sensors that would receive information from the environment and send it back to the brain. According to P38, "well the motors are helping the robot and the ultrasound, but mostly it's the brain that's doing it." Further, P38 talked about the importance of sensors and making the robot move, "well, when the light sensor senses the white, black or gray it sends it to the brain and then it tells it...And then it, the brain, tells it the motor to go." Similarly, P39 noted that "[t]he ultrasonic sensor will sense where things are and then let you pick the clear route or if there's something ahead of you." These examples illustrate that participants saw a causal relationship amongst design components. Such data showed that participants' knowledge construction and conceptualization through a systems thinking perspective was reinforced by mapping understandings of their own bodies to the robotics components. As with systems thinking, embodied cognition was not a curriculum objective taught explicitly by the instructors.

\subsection{Associations}

Associations refer to participants' acts of connecting engineering design processes and actions to their own extant knowledge and behaviors. Many of these associations seemed reflective of embodied cognition as they were rooted in or built upon students' understandings of their own or others' bodies and concomitant physicality.

First, participants would conceive of the robot as their own body and physically embody the actions of the robot - acting out movements and sensor responses. At this level the robots actions are mapped onto the student's own body. For example, when P2 notes: 
A model of how children construct knowledge and understanding of engineering design

I remember it, one motor goes to the right, because the light it absorbs and one goes to the white.

So it goes like [hand motions indicate path of robot] along the line.

She can be observed assuming the role of the robot and using her hands to support her own and others' understanding of the robots', which demonstrates responses (cf. Fadjo, 2012; Petrick, Berland, \& Martin, 2011). Similarly, P4 enacts the robots' dumping motion stating: "It dumps them [while illustrating with body motions and hand movements how the robot dumps the bricks]." Students were observed articulating understandings of the robots through an allocentric (third person perspective). This first step away from the self's physicality maps student's understanding of their own physicality onto the robot. The transition from the zero separation (direct embodiment) to the third person perspective (allocentric view) becomes evident when P11 uses the second person rhetorical device ("you know, when you...") that allows the speaker to and invites his interlocutor to assume the role of the robot with the description: "Sometimes it's really useful because you know, like, like a guy will be like running behind you and you'll be going..." More directly, the students' mapping of their own physical characteristics onto the robot, illustrates an allocentric understanding rooted in their own physicality like making connections with sight: "It's actually the eyes of the robot" (P1). At the third level of separation, students were observed extrapolating physical characteristics of other biological organisms onto the robot. Such understandings are (potentially) illustrative of associations:

We're using the kind of, the ultrasound sensor... Like, it's like the bat, cuz, since it doesn't have eyes, it sends out sound and if it bounces back it knows where something is, so it knows not to go there (P8).

Yes, Um, it can, it kinda like sends a beam kinda thing, like bats. And it goes like, it goes like forward and back and however long it takes it knows how, the difference between it is (P7).

A chaining of associations was derived from the student's own physicality, extended to another organism, and then used to understand the robot, e.g. student's sight $\approx$ bat's echolocation $\approx$ robot sensing.

Participants also exhibited frequent connection building to other complex systems. This frequently occurred when participants were asked by researchers to describe the purpose of a particular system element. Participants would often respond with a simile. For example, when asked to describe the purpose of the brick, the robots' CPU to which all motors and sensors are connected, participants referred to it as the brain.

The brain is like the computer for the robot. Without the brain you can't make it do anything (P2).

The brain has like all the memory like a real brain does and it has like, like you have to have the cables to like plug it in and like plug it into the cables so it can, so it can work (P35).

The motors are helping the robot and the ultrasound, but mostly it's the brain that's doing it (P18).

The associations between system elements of the robot and prior knowledge, including those rooted in corporality, were important for helping participants explain and understand the engineering design of their robots. Owing to their abilities to make such associations between the system elements of a robot and parts of living organisms, and consequently better comprehension of the relationships among those parts, students constructed a systems thinking conceptual framework for understanding engineering design within the context of robotics focused activities and tasks. Associations among robots and students' existing schema of their own physicality and that of other living organisms exemplify the roles of embodied cognition and systems thinking in children's robotics design. Further, both approaches serve as complementary frameworks that guide children's design process. 


\subsection{Design Decisions}

Participants' design decisions directly reflected their growing knowledge base in engineering design within a robotics context and their perceptions of the design elements needed in order to complete tasks. Students constructed knowledge of engineering design through an iterative process beginning with a base-build, followed by customization, and then continued with incremental refinement. Though this process was essentially trial-and-error, the researchers observed that participants' approaches were purposeful and informative, which resulted in meaningful improvements and increased comprehension of the designs with every iteration. Refinements to the base robot were made as participants received more information about the task or following tests of the robot's task performance. P24 illustrates this approach of starting with a base robot that had a set of wheels attached to motors that were connected to a mounted brick:

We find [sic] already basic chassis, as they're called, like a basic frame for it. And from there we build on to it on our own. Like we're going the wedge and the cage on the back. So, that's how you basically do it.

As participants customized robots to accomplish specific tasks, they evidenced a sense of design as an iterative process:

I think they're trying to build more attachments so we can make it better (P6).

We're trying to make it better; we are learning from our mistakes that we made (P10).

Yea, we're trying to make it like um, better so we can, we're adding stuff so we can push the other person out of the way (P14).

Often, the design decisions were based on a participant's ability to identify and plan for current task requirements. As P6 described, "We're trying to do that [obstacle] course. Like we're going to pick up the carrots and try pick up some of the other stuff too. We're just using different attachments. Like maybe a hook for one and something with Velcro for another." This also became apparent in P13's assessment of obstacle avoidance, "We wanted to keep [ultrasonic sensor] low because a lot of the obstacles were lower and we wanted it to come really close contact with the block" after observing the test track. P13 responded to both the task as well as the environmental factors in which the task is situated. Similarly, P4 noted in regards to the light sensor that "we have it face down cuz we want it to look for a black line so that it knows when to dump the cotton," which further illustrated participants' awareness of the task and the associated environmental considerations.

Though many examples highlighted forethought when making design decisions, occasionally, as with P6 and group, participants adopted a seemingly more haphazard approach: "Well, we're just kind of testing them all out to see which one will work the best." Other participants demonstrated that they were able to anticipate potential problems and made design decisions accordingly. This was observed as participants planned to prevent robots from falling over during a sumo competition in which two robots went head-to-head to push each other out of a ring:

Well we added weight on the back so it doesn't tip over (P12).

We put a big rectanglish wedge but instead we put hooks on the front so it would pick it up. It would pull it over itself and drop in to a little box on it so it wouldn't fall (P24).

Design decisions became increasingly deliberate as competitions drew nearer and towards the end of each camp week as challenges grew more complex. Such design decisions were frequently based on participants' associations of prior knowledge and articulations of the robot as a system. 


\subsection{Challenge}

The category challenge refers to any of the difficulties that participants encountered during their engineering design tasks. The tasks often proved challenging for participants due to the dynamic nature of the environment and complexity of the real world problem spaces. Additionally, the challenges were frequently compounded when robots did not exhibit the behaviors that participants had believed they had designed into the programming. Challenges included unexpected and unaccounted for changes to the environment, such as other robots being present in the playing field and other novel situations not accounted for in the initial design. These challenges gave rise to better problem solving strategies, as groups were able to refine their robot's design:

At first we didn't get this to detect...the opponent so we had to go back and fix that (P17).

The part I'm worried about is actually not building the frame, really, really the two attachments. The basket is going to be, all we have to do it make a box sort of with an open top. I'm worried about how we're going to do the wedge in front, cuz that seems harder (P24).

So our original plan was to have shields right here so it doesn't walk as well. And then just have, just to have a scoop so it carries it basically. And then these would just kinda hold it in place and if it goes by it just kind of scrapes it basically (P30).

In these cases, testing buoyed participants' knowledge and understanding of design limitations and flaws, which, in turn, supported their design improvement decisions. Consequently, challenge was not a deterrent, but rather it galvanized participants into designing better robots. P36 stated, "You gotta program it, if you make a problem you gotta figure that problem out, it's fun seeing what the problem is." For many participants, design challenges surfaced when the robot did not behave in the expected manner. Often, these challenges were due to errors in participants' code, which exacerbated the perception that programming was a challenge in itself.

\subsection{Control}

Control refers to participants' sense of power over the outcome of the engineering design within the context of robotics, either the perception of control and/or actual control. Participants expressed a sense of ownership and control over the robots, which, in turn, gave them the feeling that they had a stake in completing tasks and solving problems. Participants' sense of control and ownership became more apparent during the customizing phase of the design as they decided which parts to add to the robot.

Participants learned that they could instruct and shape the robot and its behaviors through well thought out physical and program design. As P18 explained, "Well, we need to control the robot...um...we need to put parts of the robot to make this...to make it." Further, P13 emphasized that, "Using the right programming, I can program it [to do] pretty much anything as long as I have the right sensors." These statements reflect varied facets of control as P18 refers to the control through physical design whereas P13 refers to the control through program design. The participants were free to add whichever parts to the robot they deemed beneficial to completing the task. In doing so, they had complete discretion in deciding the types of sensors and attachments to be added to the robot, which, using their new found knowledge of engineering design, they were able to do. This is evidenced by P27, who, while ensuring that a crane attachment worked correctly, indicated, "We're trying to make them grab things and put them there like this," whereby the team added another motor to the robot in order to control the crane.

There was also a perception that the robot was an autonomous unit having control over its own behavior, which facilitated participants' utilization of direct embodiment strategies. This is illustrated by P30, who indicates that the robot "can tell if anyone is there and it will charge into them if it senses them. And then the light sensor keeps them in sight of the arena." Further, P31 indicated that, "What we're trying to do is see if our robot works at what we're trying to do," which presupposes a sense that the robot may do something completely 
Yuen, T. T., Stone, J., Davis, D. G., Gomez, A., Guillen, A., Price Tiger, E., \& Boecking, M.

unexpected and contrary to designed programming. There was less of a sense of control over the overall design as P41 was asked what would happen if the motors were not programmed correctly, who then responded that it would be "Pure nightmare...It'll freeze and you won't be able to do it until you figure it out." P37 noted, "Well that's mainly what it's programmed to do, then we have to go over there and turn it off." These passages highlight some participants' sense of limited control over the final design, which, as in the cases presented above, was when the robots' programs did not successfully complete the tasks.

\section{Discussion}

The categories that emerged from the data have culminated in a fluid and complementary model explaining how children construct knowledge and understanding of engineering design as facilitated by robotics projects and activities. The theory is summarized in Figure 1. These findings reinforce similar findings in the literature: namely, that the iterative process of engineering design is crucial for students' learning (Martin, 2009; Perkins, Hancock, Hobbs, Martin, \& Simmons, 1986). The participants' application of iterative design processes challenged them to accomplish tasks that required the application of cumulative knowledge across the span of a camp week. Through overlapping frameworks that use both embodied cognition associations and systems thinking, children construct knowledge of engineering design tasks by using prior knowledge to integrate new concepts into a lattice of pre-existing and more familiar schema. In the case of these participants, this schema explains how children map (analogize) the functions and attributes of living beings to robots. Embodied cognition, discussed here as extrapolation (understanding) of robots' characteristics from the students' and other's own physicality, enabled the children to better understand the robot as a system.

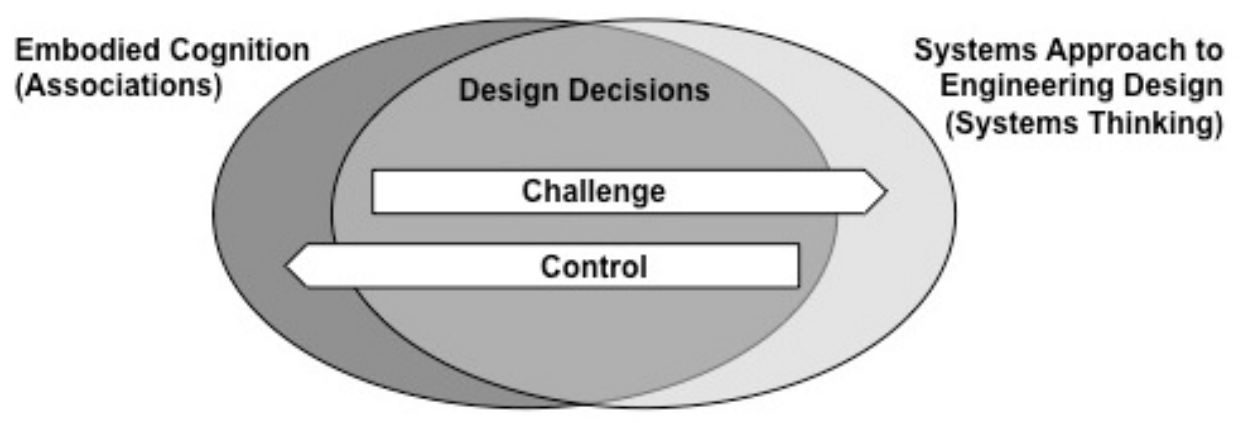

Figure 1. Two complementary conceptual frameworks explaining children's construction of knowledge and understanding of engineering design in the context of robotics.

As challenges increased in difficulty, children began to acknowledge the need for complexity in their application of engineering design. Simple analogies and mapping to students' own physicality gradually gave way to a systems thinking focus where the robot was a function of both its programming and its parts. This was significant as a systems thinking approach allows learners to have deeper and more complex conceptual understandings of the problem space, the tasks, and subsequent solutions (Anderson \& Johnson, 1997; Goldstone \& Wilensky, 2008; Hmelo et al., 2000), especially when learners understand the functionality and affordances of each component in the system and use them to optimally and efficiently work in conjunction with other system components to accomplish the goal. Early in the design process, children were quick to label robot behaviors as something beyond their control; however, as children began to understand the robot as a function of its systems they felt more control over its movements and actions. The progression from associations rooted in embodied cognition to systems thinking and the acceptance of control over design and function both serve to demonstrate a better picture of children's understanding of engineering design in robotics projects.

\subsection{Limitations}

Participation in this study was voluntary, and this resulted in only a fraction of the camp participants being 
A model of how children construct knowledge and understanding of engineering design

recruited as study participants. There were several participants in the camp whose parents were missed at sign up due to the limited number of researchers or who chose not to take part in the study. It should also be noted that students in attendance at this camp were likely to have some existing interest or background in robotics or other STEM activities as this camp was offered for a price and therefore not open to everyone. Additionally, instructors for the camp were not all professionally trained teachers. Quality instruction makes a difference in the comprehension and cognitive engagement of students, and though the STEM and robotics background were present, some instructors may not have been able to clearly guide and engage children in the concepts of engineering design. The research team were guests of the camp and were unable to train or comment on instruction. Lastly, though the study lasted for 6 weeks, individual camp sessions were only five days in duration. Five days is a very limited amount of time for children to master the complicated concepts of engineering design, even given the authentic, concrete, and hands-on activities in the robotics activities.

\section{Conclusions}

This study took an in-depth look into how children construct knowledge and understanding of engineering design within a robotics context. The resultant theory describing children's conceptual frames for understanding robots in engineering design provides educators and instructional designers with recommendations for better facilitating engineering design at the elementary and middle school level. As this study demonstrated, children become meaningfully engaged in complex and higher order thinking during engineering design activities within the context of robotics, which may lead to success in other areas of engineering design within a formal curriculum.

\section{References}

Anderson, V., \& Johnson, L. (1997). Systems Thinking Basics: From Concepts to Causal Loops. Waltham, MA: Pegasus Communications, Inc.

Assaraf, O. B., \& Orion, N. (2010). System thinking skills at the elementary school level. Journal of Research in Science Teaching, 47(5), 540-563.

Bers, M. U. (2010). The TangibleK robotics program: Applied computational thinking for young children. . Early Childhood Research \& Practice, 12(2), 1-20.

Blikstein, P., Rand, W., \& Wilensky, U. (2007, July). Just a cog in the machine: participatory robotics as a tool for understanding collaborative learning and decision-making. In Proceedings of the 8th International Conference on Computer Supported Collaborative Learning (pp. 84-86). International Society of the Learning Sciences. http://dx.doi.org/10.3115/1599600.1599614

Committee on K-12 Engineering Education. (2009). Engineering in K-12 Education: Understanding the Status and Improving the Prospects. Washington, DC: The National Academies Press.

Fadjo, C. L. (2012). Developing computational thinking through grounded embodied cognition. Columbia University, New York, NY, USA.

Frank, M. (2002). Characteristics of engineering systems thinking - a 3D approach for curriculum content. Systems, Man, and Cybernetics, Part C: Applications and Reviews, IEEE Transactions on, 32(3), 203-214. http://dx.doi.org/10.1109/TSMCC.2002.804450

Glaser, B. (1965). The constant comparative method of qualitative analysis. Social Problems, 12(4), 436-445. http://dx.doi.org/10.2307/798843

Glaser, B., \& Strauss, A. (1967). The Discovery of Grounded Theory: Strategies for Qualitative Research. New Brunswick, NJ: Aldine Transaction.

Goldman, R., Eguchi, A., \& Sklar, E. (2004, June). Using educational robotics to engage inner-city students with technology. In Proceedings of the 6th International Conference on Learning Sciences (pp. 214-221). International Society of the Learning Sciences.

Goldstone, R. L., \& Wilensky, U. (2008). Promoting transfer by grounding complex systems principles. The Journal of the Learning Sciences, 17(4), 465-516. http://dx.doi.org/10.1080/10508400802394898

Hmelo, C. E., Holton, D. L., \& Kolodner, J. L. (2000). Designing to learn about complex systems. The Journal 
Yuen, T. T., Stone, J., Davis, D. G., Gomez, A., Guillen, A., Price Tiger, E., \& Boecking, M.

of the Learning Sciences, 9(3), 247-298. http://dx.doi.org/10.1207/S15327809JLS0903_2

Howison, M., Trninic, D., Reinholz, D., \& Abrahamson, D. (2011). The mathematical imagery trainer: From embodied interaction to conceptual learning. In Proceedings of the SIGCHI Conference on Human Factors in Computing Systems (pp. 1989-1998). New York, NY, USA: ACM. http://dx.doi.org/10.1145/1978942.1979230

Katehi, L., Pearson, G., \& Feder, M. (2009). Engineering in K-12 education. Committee on K-12 Engineering Education, National Academy of Engineering and National Research Council of the National Academies.

Kolodner, J. L., Camp, P. J., Crismond, D., Fasse, B., Gray, J., Holbrook, J. (2003). Problem-based learning meets case-based reasoning in the middle-school science classroom: Putting learning by design (tm) into practice. The Journal of the Learning Sciences, 12(4), 495-547. http://dx.doi.org/10.1207/S15327809JLS1204_2

Lakoff, G., \& Johnson, M. (1999). Philosophy in the flesh: The embodied mind and its challenge to western thought. New York, NY: Basic Books.

Lakoff, G., \& Núñez, R. E. (2000). Where mathematics comes from: How the embodied mind brings mathematics into being. New York, NY: Basic Books.

Lord, S. M., Camacho, M. M., Layton, R. A., Long, R. A., Ohland, M. W., \& Wasburn, M. H. (2009). Who's persisting in engineering? A comparative analysis of female and male Asian, Black, Hispanic, Native American, and White students. Journal of Women and Minorities in Science and Engineering, 15(2), 167-190. http://dx.doi.org/10.1615/JWomenMinorScienEng.v15.i2.40

Martin, T. (2009). A theory of physically distributed learning: How external environments and internal states interact in mathematics learning. Child Development Perspectives, 3(3), 140-144. http://dx.doi.org/10.1111/j.1750-8606.2009.00094.x

Mehalik, M. M., Doppelt, Y., \& Schuun, C. D. (2008). Middle-school science through design-based learning versus scripted inquiry: Better overall science concept learning and equity gap reduction. Journal of Engineering Education, 97(1), 71-85. http://dx.doi.org/10.1002/j.2168-9830.2008.tb00955.x

Moffett, G. E., Weis, A. M., \& Banilower, E. R. (2011). STEM Fields. Chapel Hill, NC: Horizon Research, Inc.

Moffett, G. E., Weis, A. M., \& Banilower, E. R. (2014). Engineering is elementary: Impacts on students historically-underrepresented in STEM fields. Chapel Hill, NC: Horizon Research, Inc., 20.

National Science Foundation, National Center for Science and Engineering Statistics. 2015. Women, Minorities, and Persons with Disabilities in Science and Engineering: 2015. Special Report NSF 15-311. Arlington, VA. Available at http://www.nsf.gov/statistics/wmpd/.

Núñez, R. E., Edwards, L. D., \& Matos, J. F. (1999). Embodied cognition as grounding for situatedness and context in mathematics education. Educational Studies in Mathematics, 39(1-3), 45-65.

Ohland, M. W., Sheppard, S. D., Lichtenstein, G., Chachra, D., \& Layton, R. A. (2008). Persistence, engagement, and migration in engineering. Journal of Engineering Education, 97(3), 259-278. http://dx.doi.org/10.1002/j.2168-9830.2008.tb00978.x

Perkins, D. N., Hancock, C., Hobbs, R., Martin, F., \& Simmons, R. (1986). Conditions of learning in novice programmers. Journal of Educational Computing Research, 2(1), 37-55. http://dx.doi.org/10.2190/GUJT-JCBJ-Q6QU-Q9PL

Petrick, C., Berland, M., \& Martin, T. (2011). Allocentrism and computational thinking. In G. Stahl, H. Spada, \& N. Miyake (Eds.), Connecting Computer-Supported Collaborative Learning to Policy and Practice: CSCL2011 Conference Proceedings (Vol. 2, pp. 666-670). Hong Kong: International Society of the Learning Sciences, Inc.

Reza, S. \& Ijaz Baig, M. (2015) A study of inverted classroom pedagogy in computer science teaching. International Journal of Research Studies in Educational Technology, 4(2), 19-30. http://dx.doi.org/10.5861/ijrset.2015.1091

Shenton, A. K. (2004). Strategies for ensuring trustworthiness in qualitative research projects. Education for Information, 22(2), 63-75.

Slangen, L., van Keulen, H., \& Gravemeijer, K. (2011). What pupils can learn from working with robotic direct 
A model of how children construct knowledge and understanding of engineering design

manipulation environments. International Journal of Technology and Design Education, 21(4), 449-469. http://dx.doi.org/10.1007/s10798-010-9130-8

Strauss, A., \& Corbin, J. (1998). Basics of Qualitative Research: Techniques and Procedures for Developing Grounded Theory. Thousand Oaks, CA: SAGE Publications, Inc.

Tai, R. T., Liu, C. Q., Maltese, A. V., \& Fan, X. T. (2006). Planning early for careers in science. Science, 312 , 1143-1145. http://dx.doi.org/10.1126/science.1128690

Tornatzky, L. G., Macias, E. E., \& Jones, S. (2002). Latinos and information technology: The promise and the challenge. Claremont, CA: The Tomás Rivera Policy Institute.

Verner, I. M., \& Ahlgren, D. J. (2004). Robot contest as a laboratory for experiential engineering education. Journal Educational Resources Computing, 4(2), 2. http://dx.doi.org/10.1145/1071620.1071622

Wilensky, U., \& Resnick, M. (1999). Thinking in levels: A dynamic systems approach to making sense of the world. Journal of Science Education and Technology, 8(1), 3-19. http://dx.doi.org/10.1023/A:1009421303064

Williams, D. C., Ma, Y., Prejean, L., Ford, M. J., \& Lai, G. (2007). Acquisition of physics content knowledge and scientific inquiry skills in a robotics summer camp. Journal of Research on Technology in Education, 40(2), 201-216. http://dx.doi.org/10.1080/15391523.2007.10782505

Wilson, M. (2002). Six views of embodied cognition. Psychonomic bulletin \& review, 9(4), 625-636. http://dx.doi.org/10.3758/BF03196322

Yao, J. T. P., \& Roesset, J. M. (2001). Suggested topics for a civil engineering curriculum in infrastructure management. Public Works Management \& Policy, 5(4), 308-317. http://dx.doi.org/10.1177/1087724X0154006

Yurtseven, M. K., \& Buchanan, W. W. (2012). Educating undergraduate students on systems thinking and system dynamics. Paper presented at the Technology Management for Emerging Technologies (PICMET), 2012 Proceedings of PICMET '12. 
Yuen, T. T., Stone, J., Davis, D. G., Gomez, A., Guillen, A., Price Tiger, E., \& Boecking, M. 